\title{
Breaking the ice: a work domain analysis of icebreaker operations
}

\author{
Magnus Boström ${ }^{1}$
}

Received: 21 November 2017 / Accepted: 6 April 2018 / Published online: 25 April 2018

(c) The Author(s) 2018

\begin{abstract}
Icebreakers are special-purpose ships designed to operate in different ice-covered waters, either independently or during assistance of weaker ships. In the Baltic Sea, as well as elsewhere, they are essential for maintaining continuous sea transport services during wintertime. Icebreaker operations are complex, and every situation in which a vessel requires assistance is unique, due to, e.g. changing ice and weather conditions, geographical location or language proficiency of the crew on board the icebreaker or assisted vessel. The icebreaker crew has considerable freedom to adapt to each situation, yet, for safe operations, there are constraints to which the crew has to conform. The study presented in this paper aims at identifying the constraints on nautical officers on board icebreakers during operations, as well as special situations that increase cognitive load. A work domain analysis based on a group interview with nautical icebreaker officers shows the multitude of tasks performed on board icebreakers. Furthermore, it identifies constraints specific to icebreaker operations such as ice assessment and direct icebreaking, but also generic constraints such as language and communication skills. At times, safety and efficiency come into conflict, resulting in a trade-off between the two. When that happens, safety gets priority, and the operation stops until the situation has been evaluated. In addition, several situations that increase cognitive load are identified, with the common denominator that they add elements of uncertainty, e.g. severe weather and technical malfunctions. Finally, further research within the area of icebreaker operations is recommended, with a continued focus on the system constraints, and their potential for system improvement.
\end{abstract}

Keywords Maritime $\cdot$ Constraint $\cdot$ Theory of constraints $\cdot$ Cognitive load $\cdot$ Socio-technical system $\cdot$ Communication

\section{Introduction}

When ice conditions are severe in the Baltic Sea, Swedish and Finnish icebreakers jointly assist merchant vessels to ensure safe navigation. The icebreaker assistance is performed either as indirect assistance, e.g. guidance via waypoints indicating the most favourable way through the ice, or as direct assistance, via icebreaking. The latter includes, among other operations, breaking loose a vessel that is beset in ice, and escorting it towards lighter ice conditions from where the vessel again can proceed on its own. As suggested by previous research, a voyage through ice adds a number of fundamentally precautious aspects compared to shipping in open water, such as severe weather conditions, ice crushing pressure on the hull (Kujala and Arughadhoss 2012) and

Magnus Boström

magnus.bostrom@lnu.se

1 Kalmar Maritime Academy, Linnaeus University, 39182 Kalmar, Sweden icing, the accumulation of ice on the superstructure of the vessel (Snider 2012). In addition, direct icebreaking involves another inherent risk; to be able to break loose or escort another vessel, the icebreaker needs to pass close by and operate in close vicinity to the assisted vessel (House et al. 2010). The small distance between icebreaker and assisted vessel can be less than ten metres, and consequently, there is little room for error (Buysse 2007). Damage can be caused by the ice itself or as a direct result of icebreaker assistance (Buysse 2007; House et al. 2010); with just a slight deviation from the planned manoeuvre, the icebreaker and the assisted vessel might collide. Research suggests that the effects of a collision or allision are multifactorial, and include putting human lives at risk, severe damage to the environment, and costly operational disturbances (Chai et al. 2017; Karahalios 2014). Furthermore, with several vessels requiring simultaneous assistance during tough ice conditions, direct icebreaking can be an uninterrupted activity for up to several days, potentially increasing fatigue (Akhtar and Utne 2014; Hetherington et al. 2006). Previous studies have linked 
fatigue to loss of concentration and disruption of cognitive functions (Chambers and Main 2015) and adverse decision making (Strauch 2015). All these factors taken together make icebreaker operations highly demanding and associated with great risk.

Previous studies of maritime operations have several limitations, which affect our current understanding of that area. Risk analysis of maritime operations and their environmental impact have at large been limited to open water operations during ice free seasons (Valdez Banda et al. 2016). Studies on ice navigation have largely been descriptive, for example, describing convoy operations (Goerlandt et al. 2017), defining common accidental scenarios and their frequencies (Valdez Banda et al. 2015) and identifying hazards of winter navigation such as categorization of ship damages and their consequences (Jalonen et al. 2005). Less researched are studies focusing on possible actions for improvements within the area of ice navigation.

Operator-oriented research is scarce within the area of ice navigation. Recently, deriving from a risk management model of winter navigation, Valdez Banda et al. (2016) recommend improved navigational training and safety and risk management training to lessen the risk of failures in human performance. Furthermore, they also suggest efficient use of electronic navigational tools. Similarly, Boström and Österman (2017) conclude that more ice navigation training would increase the operational safety during icebreaker operations, and that the past track and speed of other vessels is valuable information that, if made available through, e.g. an ECDIS (Electronic Chart Display and Information System), would have a positive effect on the safety and efficiency of ice navigation. Nonetheless, within ice navigation, few studies have addressed the human role in complex systems, where humans rely on technology, but still play an important part.

In complex systems with many uncertainties, it can be easier to describe the constraints imposed on an operator, rather than prescribe the correct procedure for every possible situation. Vicente (1999) defines constraints as something that limits our behavioural repertoire by removing degrees of freedom; degrees of freedom, on the other hand, offer possibilities for our behaviour. This is often exemplified with Simon's parable of the ant on the beach (Simon 1996; Vicente 1999). An ant crossing a beach follows what seems an irregular and complex path, constantly turning and stopping. This path, however, is not only the result of the ant itself (such as its physiology and psychology), but also dependent on the constraints imposed by the surrounding environment. Another observation about the ant made by Vicente (1999) is that different ants would perform differently when crossing that same beach because there is much variance in the object's actions. Still, the beach and the constraints imposed by it remain relatively constant; thus, 'a description of the beach is a very useful thing to have because it is relatively invariant over particular initial conditions, task goals, and trajectories. It provides a relatively stable object that can be analyzed' (Vicente 1999). The parable of the ant illustrates that there are constraints that govern the way people act. Within the context of icebreaking, the nautical officer, just as the ant, has considerable freedom to act; yet, the constraints limiting this freedom are constant and affect all officers equally.

With this in mind, the aim of this study is to identify the constraints on nautical officers on icebreakers during operations, and to distinguish any situations that further increase cognitive load.

The concept of constraint is paramount to this study. To illustrate its importance, a central theory from the field of business management is used. Initially developed by Eliyahu Goldratt in the mid 1980s, the Theory of Constraints (TOC) focuses on the weakest link to improve system performance (Şimşit et al. 2014). TOC rests upon the assumption that systems must have at least one constraint; if this were not true, corporations would make unlimited profit (Rahman 1998). Therefore, within TOC, a constraint is 'anything that limits a system from achieving higher performance versus its goal' (Goldratt 1988). Furthermore, a constraint should be viewed as an opportunity for improvement, rather than a hindrance (Rahman 1998). Turning the philosophy of TOC into practice involves a circular process that begins and ends with an examination of the system constraints (Goldratt 1988; Ronen and Spector 1992). The goal of TOC is to dissolve the constraints, thus continuously improving the overall performance of the system. Since existing constraints are turned into enhancements, new constraints will emerge creating bottlenecks in the system, making it critical to always returning to the system constraints.

To the best of the author's knowledge, this is the first time a Work Domain Analysis (WDA) has been performed on icebreaker operations. In the light of TOC, a thorough understanding of the work domain, as well as an identification of the constraints are crucial steps towards improving the operational safety of icebreaker operations. The introduction of TOC at this point serves two purposes. First, since TOC and WDA both emphasize the identification of constraints, TOC legitimizes WDA as a potent way of depicting a system and its need for improvement. Second, the circular reasoning of TOC serves as a reminder of why the continuous process of identifying system constraints is important. Only by addressing major constraints can system performance be improved, uttermost to identify potential risks for human lives at sea. However, neither WDA nor TOC itself provides solutions to the identified constraints. Some improvements, or ways to mitigate the effects of constraints, may arise from this study, but more likely, they will be the result of future research. The main contribution of this study is to provide a 
systematic description of icebreaker operations, from which future research can address specific concerns. That is also the reason for initiating with the first step of the Cognitive Work Analysis at this moment; before the effects of constraints can be determined they need to be identified and their interrelation understood. After that, further efforts and resources can be directed towards areas where research is most needed.

The remainder of the article is structured as follows. Section 2 describes the complexity of icebreaker operations. Section 3 introduces Work Domain Analysis, the initial step of Cognitive Work Analysis (CWA). Then, Sect. 4 presents the method for data collection and procedural steps for modelling the Abstraction Hierarchy ( $\mathrm{AH})$, followed by a presentation of the results in Sect. 5. In Sect. 6, the results are discussed in the light of other WDA studies in general, as well as previous research in winter navigation in particular. Finally, Sect. 7 offers conclusions as well as recommendations for future research within the field of icebreaker operations.

\section{The complexity of icebreaker operations}

Vicente (1999) describes several factors that make systems complex by 'increasing the demands on workers and system designers'. Many of these factors can be seen in icebreaker operations. When viewing icebreaker operations as a system, numerous entities are distributed in different locations and social interactions are essential for the system to function properly. Icebreaking involves a high degree of potential hazard as safety margins are small and collisions can have severe consequences. Furthermore, a vessel is a dynamic system in the way that effectiveness of actions cannot be momentarily observed, making it necessary to plan well ahead. Finally, there is a degree of uncertainty in the information that is available to the icebreaker officers, as well as frequent disturbances and unanticipated events that require adaptation. Moreover, an operator working within a sociotechnical system is subject to many stressors. Common environmental conditions that may induce stress include time pressure, work load and overload, fatigue from prolonged work or sleep deprivation, noise and ambient temperature (Bourne and Yaroush 2003), and the way these stressors are handled by the operator is paramount for the outcome of an operation. Stress can have either beneficial or degrading effects on performance depending on, among other factors, the intensity of the stressor and the skill of the performer. Light stress has the potential to facilitate performance. At moderate levels, performance may be upheld by recruitment of further, previously unused, resources (Hockey 1997). Finally, at high levels of stress, performance will degrade or even fail (Bourne and Yaroush 2003). Cognitive symptoms of stress may lead to problems related to concentration, decision-making, memory and reflection skills (Elfering et al. 2017), skills indispensable for icebreaker operations. However, contrary to Elfering et al. (2017), and to their own expectation, Belling et al. (2015) showed that performance was not significantly affected by time constraint during their trials.

Due to the nature of their work, icebreaker officers can also be classified as control crews. Waller et al. (2004) refer to control crews as "the "brains" of the complex systems they manage, because control crews are responsible for interpreting information from multiple systems and making accurate decisions during abnormal, time-pressured, high-workload situations'. Moreover, periods of high workload are clearly contrasted with periods of lower workload when the crew can prepare for future non-standard situations, by planning for the unknown.

\section{Work domain analysis}

For analysing complex socio-technical systems there are many available methods, broadly termed Cognitive Task Analysis, that can be used to determine, describe and analyse an operator's cognitive process during task performance (Stanton et al. 2013). One of these methods is the Cognitive Work Analysis (CWA), which is a framework for modelling domains. Previous research has been carried out within domains such as railroad crossings (Salmon et al. 2015), road transportation (Birrell et al. 2012), operation of motorcycles (Regan et al. 2015), operation of submarines (Stanton and Bessell 2014), military doctrine and strategy development (Naikar et al. 2014) and training-system definition and acquisition (Naikar and Sanderson 1999), as well as the health care domain from a patient perspective (Dhukaram and Baber 2015) and management of nurses (Effken et al. 2011). While the CWA framework offers researchers tools for modelling the work constraints necessary for system design development, it is unsuitable for organizational design development. As a result, Xiao and Sanderson (2014) developed the Organizational Constraints Analysis framework by integrating organizational theories with a CWA approach, which proved suitable for modelling of organizations.

With a CWA approach, the emphasis is on the constraints of the system. Compared to many other methods, which aim to describe how work is actually carried out, the CWA can be seen as a description of the field, in which different tasks are carried out. Within this field, the actor is free to decide his or her own course of action, only limited by the constraints set by the system or nature of work. The procedure for a CWA differs depending on the nature of the task that is to be analysed, but could include some or 
all of the following analyses: work domain analysis, control task analysis, strategies analysis, social organisation and cooperation analysis and worker competencies analysis (Stanton et al. 2013; Vicente 1999). For a successful completion of a CWA, it is useful for the analyst to have knowledge of the field that is being studied (Stanton et al. 2013).

The initial phase of the CWA is the Work Domain Analysis (WDA). This is used 'to represent the constraints implicit on the domain in which the activity of a system is conducted' (Birrell et al. 2012). The WDA can be illustrated with the Abstraction Hierarchy (AH), which consists of a number of levels that describe the characteristics and the constraints of a system from the most abstract top level, where the overall purpose of the system is described, through the different functions of the system to the most concrete bottom level which shows the objects or resources that the system is dependent upon (Rasmussen 1985; Vicente 1999). There is no consensus among researchers on the appropriate number or labelling of levels necessary to represent a system (Naikar 2005b). Moreover, the AH has also received criticism; Lind (2003) identified conceptual problems related to the levels of the $\mathrm{AH}$. When diverse concepts were used to characterize the different levels of the $\mathrm{AH}$, mixing e.g. activities, objects, information and financial resources, they could not be combined consistently since they belong to different contexts and levels of analysis. Furthermore, because of its vague methodology and limited theoretical basis, applying the framework to new domains can prove difficult (Lind 2003). However, 2 years later, Naikar (2005a) offered a comprehensive methodology for WDA, from which the labels in this study are adopted: functional purpose, values and priority measures, purpose-related functions, object-related processes and physical objects.

An important aspect of the $\mathrm{AH}$ is the means-ends links. The links between nodes or entries on different hierarchy levels illustrate the 'means that can be used to achieve an end' (Naikar 2005b). Likewise, the links can be exemplified with a why-how relationship; from any node in an AH, following a means-ends link upwards answers the question why that node exists, and similarly, moving downwards answers the question how that same node is realised. For example, assisting vessels is necessary because it promotes safety (why), and assistance is realised through ice assessment and direct icebreaking (how). However, it is important to note that there is no way to indicate all possible meansends relations; two ways of illustrating means-ends links are either to display all links that were purposely designed into a system, or links that indicate a person's course of action in a specific situation (Naikar 2005b). Finally, as humans are inventive, neither designers nor researchers can anticipate all means-ends links within a system, and therefore, the links between nodes in an $\mathrm{AH}$ should be seen as guidance for understanding the system, not as an exhaustive description of all possible connections.

\section{Methods for data collection and analysis}

\subsection{Data collection}

To get a thorough understanding of the constraints on nautical officers during icebreaker operations, a qualitative approach was adopted. The data necessary for the modelling of the WDA was collected through a group interview, which shares many, but not all, characteristics of a focus group interview. One distinction, though, is the extent to which the researcher makes use of group dynamics and interaction. By conducting a group interview instead of individual interviews, the synergies that emerge from the group interaction are captured, 'in other words, the group is more than the sum of its parts' (Gillham 2005). This means that the participants can elaborate on ideas brought forward by others. In contrast, with a focus group interview, the researcher is not only interested in what the participants discuss, but also the process of 'how and why individuals accept or reject others' ideas' (Stewart et al. 2007). This point is further stressed by Kitzinger (1994), stating that 'the distinguishing feature of focus groups is supposed to be the use of interaction as part of the research data'.

To elicit qualitative data, expert sampling (also known as judgment sampling) was performed. This is a nonprobability sampling method suitable when a study does not require results to be generalised (Etikan et al. 2016). The inclusion criteria for this study were that respondents must have good knowledge of icebreaking, and that the respondents as a group would represent different ranks on board. The latter was deemed important to capture views that might differ by rank and experience. In addition, self-selection was deemed acceptable as long as the inclusion criteria were met. Consequently, four icebreaker officers were purposively recruited, having extensive knowledge of icebreakers and their operations; they had each accumulated experience from 5 to 12 seasons of Baltic Sea icebreaking. The group constituted of 1 master, 1 chief officer and 2 second officers. The interview, which was digitally recorded and later transcribed, was conducted in Swedish and lasted for approximately $2.5 \mathrm{~h}$.

Before the interview, the participants were briefed about the purpose of the interview as well as the general structure of a WDA. The interview was semi-structured and centred around the levels of the WDA, and the questions were chosen to mirror these levels. Table 1 illustrates the themes that were covered during the interview along with initial questions and some follow up probes. However, the respondents were encouraged to address additional themes that they thought relevant, so the questions do not reflect 
Table 1 Interview themes

\begin{tabular}{|c|c|c|}
\hline Theme & Initial questions & Example of follow up questions \\
\hline Functional purpose & $\begin{array}{l}\text { Define your main activity } \\
\text { What do you do? }\end{array}$ & $\begin{array}{l}\text { Which actors do you co-operate with? } \\
\text { What is your contribution to society? } \\
\text { What are your constraints? }\end{array}$ \\
\hline Values and priority measures & $\begin{array}{l}\text { What is a successful icebreaker operation? } \\
\text { What is a good winter season? }\end{array}$ & $\begin{array}{l}\text { E.g. escort, no damages, speed, waiting time, customer } \\
\text { satisfaction, etc. } \\
\text { Are there challenges to value fulfilment? }\end{array}$ \\
\hline Purpose-related functions & $\begin{array}{l}\text { Describe icebreaker operations from your perspective. } \\
\text { What elements are involved? }\end{array}$ & $\begin{array}{l}\text { Does this vary with rank or position? } \\
\text { If yes, how? }\end{array}$ \\
\hline Object-related processes & What basic processes does the icebreaker perform? & How are they related to the functions described earlier? \\
\hline Physical objects & What resources do you primarily rely on? & $\begin{array}{l}\text { E.g. physical or abstract. } \\
\text { Why are they important? }\end{array}$ \\
\hline Special situations & $\begin{array}{l}\text { Are there any special situations that make operations } \\
\text { more difficult? } \\
\text { What elements are problematic? }\end{array}$ & $\begin{array}{l}\text { E.g. time of day, time of year, time at disposal, location, } \\
\text { etc. } \\
\text { E.g. 'I hope that doesn't happen' }\end{array}$ \\
\hline
\end{tabular}

the complete interview. When conducting the group interview, it was crucial to prevent one or a few persons from dominating the group (Denzin and Lincoln 2011). However, with a group of only four participants, the researcher was able to follow up both verbal and non-verbal cues as well as steer the interview in the desired direction. The relatively small group also made transcribing feasible; all data from the interview could be attributed to the correct participant, something that can be difficult to manage with a large group size (Gillham 2005).

\subsection{Modelling the abstraction hierarchy}

To analyse the transcribed interview data, a method of thematic analysis was used. The necessary steps included an initial reading of the transcript, followed by coding of interesting features of the data, which were subsequently structured into potential themes. The themes were then viewed against the entire data set and refined until they clearly reflected the data contained in them. Finally, appropriate labels were chosen for the themes. For a more detailed description of the process, see Braun and Clarke (2006). Furthermore, it should be noted that this study employed a theoretical thematic analysis to identify the themes. According to Braun and Clarke (2006), this is a 'top-down' method where the analysis is 'driven by the researcher's theoretical or analytic interest in the area', resulting in codes and themes that fit a specific research question. For this study, this meant that the resulting themes were mainly key functions or constraints to icebreaker operations, and could, therefore be assigned to the appropriate levels of the WDA.

The AH was constructed and revised in three steps. The first version was done prior to the interview, based on the researcher's pre-understanding of the subject, experience gained through participation in work on board Swedish icebreakers, and by reading internal training documentation.
The first version was presented to the respondents during the interview and used to start the discussion. After the interview, the second version of the $\mathrm{AH}$ was modelled to include the respondents' expertise, hence it was more detailed and complex. Finally, before arriving at the third and final version, a subject matter expert was consulted to discuss the $\mathrm{AH}$ and the conclusions derived from it. This subject matter expert was an experienced icebreaker officer but had not taken part in the group interview or worked with the WDA at any previous stage.

\section{Results and analysis}

The results are presented in two sub-sections. The first section presents the WDA of icebreaker operations and the constraints on its personnel. The second section gives an account of situations that further increase cognitive load. The quotes from the respondents have been selected to illuminate different stories, and paint a rich description of the issues at hand. Furthermore, the quotes have been translated into English by the author, with the intent to maintain the style of the language throughout the translation process.

\subsection{Icebreaker work domain analysis}

Figure 1 shows the abstraction hierarchy of the WDA, derived from the collected data; it represents the functional structure of a system and its constraints, which limit the behavioural freedom of the operator. As such, it defines the boundaries, which the operator has to conform to. The individual levels are explained in further detail below.

Even though a WDA depicts the system as a whole, it can be helpful to look at specific parts in detail. By isolating one node at a time, the effect of that constraint can be evaluated by following the means-ends links to the levels 


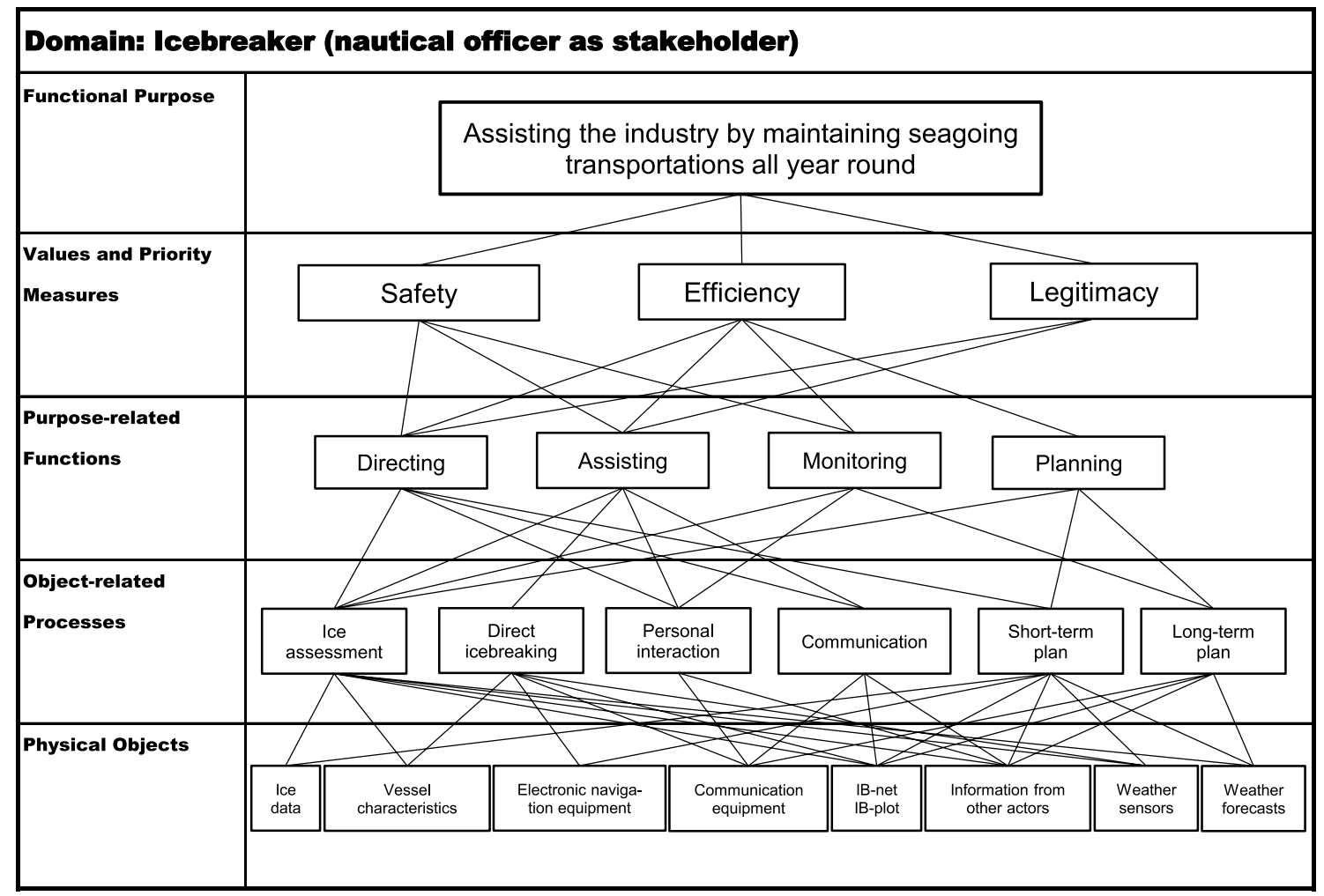

Fig. 1 Abstraction hierarchy (AH) of icebreaker operations

above and below. For example, ice assessment (an objectrelated process) connects to all purpose-related functions, which makes it reasonable to assume it to be an important skill, and consequently, lacking that skill is a serious constraint to the icebreaker as a system. If ice assessment is a skill that is primarily acquired through experience, care must be taken when assigning new crewmembers on board, so that ice assessment does not become too large of a constraint. Another example of looking at a small part of the WDA could be to identify physical objects that are linked to many processes. For example, if weather sensors are linked to many object-related processes, the sudden failure of such sensors would be a constraint. That could call for a restructuring of the system to improve redundancy in that area.

\subsubsection{Functional purpose}

The actions of an icebreaker can be viewed at different levels. At a local level it physically crushes sea ice and gets beset vessels into motion, and at a large-scale geographical level it assists vessels from their port of departure to their destination. However, these descriptions merely label what the icebreaker does, not the actual purpose. The overarching purpose, however, is to ensure the continuous operation of production industries, by providing them with the necessary resources for the shipping out of their products. In addition to manufactured goods, the transportation of people is another business that needs the assistance of icebreakers, and consequently, the purpose of the icebreaker is condensed into assisting the industry by maintaining seagoing transportations all year round.

\subsubsection{Values and priority measures}

With the domain purpose defined very broadly, the respondents were then asked to specify more detailed domain values, i.e. defining the criteria used for assessing whether the icebreaker successfully fulfils its purpose. The first value mentioned was the official goal set by the Swedish government, which states that a merchant vessel in the Baltic Sea should not have to wait more than four hours before receiving icebreaker assistance. A more general goal was expressed as 'getting them from the ice edge to their destination, and back, without any incident'. Another respondent said that he rarely reflected upon the pre-defined goal; maintaining a reasonable speed through both ice and open water through a safe assistance is paramount in all conditions. Furthermore, in addition to being quick, it is at least equally important to arrive within a set time window, at the time that has been promised; 'you 
have given a time of arrival, we will be at the pilot station at that time, and then you arrive at that time, then it feels good, we managed to keep what we promised'. Since there are many uncertainties involved in the operation, it is not uncommon for the icebreaker to be delayed. In such a situation it is of utmost importance to brief everyone standing by, e.g. assisted vessels, pilots and ship agents, i.e. keep the waiting time of others to a minimum.

Safety, both internal (e.g. safety of crew) and external (safety of other vessels) is an important priority measure. Striving at maintaining an operation free from accidents is a domain value, something that is dependent on detailed planning prior to the operation, so that any factors that might pose a safety threat can be addressed. One way safety is addressed on board is through company organised safety seminars or toolbox talks which include topics such as personal safety, fatigue and how to act if one feels unfit to perform a certain task.

Efficiency is manifested in several ways. A cooperation agreement between Finland and Sweden, which entered into force in 2011, stipulates that the nearest icebreaker will assist the merchant vessel, regardless of the vessel's port of destination or the flag of the icebreaker. This flexibility has increased the efficiency considerably, i.e. reducing waiting time for assistance. Furthermore, when multiple vessels require assistance from the same icebreaker, they are not necessarily assisted on a first-come, first-served basis. After consultation with pilot stations and ship agents, priority is given vessels that have available pilots and births. There is no reason for the icebreaker to offer immediate assistance to a merchant vessel that will have to wait, regardless. Hence, information from, and communication with, other actors becomes crucial for the efficiency of the icebreaker.

Maintaining legitimacy is also an important domain value, towards the assisted vessels but also with regard to the general opinion. The latter involves both people that are directly affected by the icebreaker, e.g. people in the archipelago that depend on the icebreaker not destroying ice roads or snowmobile routes, but also taxpayers who feel that the icebreakers are not used to their full potential. One respondent offered a vivid example:

I was on board [a Swedish icebreaker] during those two winters when there was lots of ice in the Baltic, and we received lots of criticism for being in Antarctica instead of here. /.../ We received e-mails from the public, in which they mocked us, or were upset or angry. /.../ They think that the icebreakers are funded by taxes, which is not true today. It is rather the merchant vessels that pay for the icebreaker service; they [the merchant vessels] should be annoyed.

The above quote indicates that indirect stakeholders, even though they do not benefit directly from the service provided by icebreakers, play a part in the legitimization of icebreaker operations.

The financial aspects of icebreaking can be viewed from two different angles. From a strategic planning perspective, the national budget for the icebreaker service can be a constraint. Maintaining seagoing transportation all year round is a vital part of the infrastructure necessary for the production industry. This requires an ample number of well-functioning icebreakers, and financial resources need to be allocated to make that possible. One respondent recalled that just a few years ago, it was decided to keep one northern port open all year round, a port that previously had been closed during winter, and such a strategic decision will have a financial impact. In contrast, from a day-to-day perspective, few economic constraints affect the operation of the icebreaker. The operational budget is estimated to be suitable for a mild winter season; a master offered his view of the consequences of a winter season turning out to be more severe than expected:

When we get there, then I think it just has to work, and then it has to cost, there is no limit, to the best of my knowledge, like if we hit that level or that amount of money, then we must close a port. Everything just has to work.

However, two constraints were mentioned. First, limited internet bandwidth constrains the daily operation by reducing the icebreaker's ability to communicate with other systems, thus reducing the efficiency of the operations. Second, the number of nautical officers on board affects the safety.

You have to concentrate if there is fog all the time, and also if you constantly manoeuvre the vessel. And you work 6 by 6 all the time. And there is constant noise, vibrations, and you don't sleep that well. That's a safety aspect, a safety risk. And it is a budget issue, to have only four officers.

The respondents agreed that five officers, in addition to the master, is ideal. With two officers on the bridge at any time, a total number of five relieves the burden of having to work $6 \mathrm{~h}$, followed by only $6 \mathrm{~h}$ of rest.

\subsubsection{Purpose-related functions}

When a merchant vessel approaches and later enters ice, the icebreaker has three main functions. First, it directs the vessel, either by verbal or written instructions, on how it should proceed through the ice with as little problem as possible. This is mainly done with the use of waypoints, and for some vessels this will be enough to get them to their destination. Second, a vessel which is proceeding on its own will still be monitored by an icebreaker, until it is either fast ashore or has left the area monitored by the icebreaker. Finally, if the vessel gets beset in ice, the icebreaker needs to physically 
assist it until it reaches lighter ice conditions, and once again can proceed on its own. Manoeuvring an icebreaker in close proximity to another vessel takes some time to master; some people learn to master it to perfection, others to an intermediate level. One respondent expressed it colourfully:

It is like a feeling inside your body, like balance. Some have that feeling and improve upon it, others can mechanically train up to a certain level, like a sequence that you repeat and learn to recognize. Other people have the feeling that the vessel is an extension of the body's motion sensors and feel and observe how the vessel moves before the instrumentation indicates any rate of turn. Both can be super skilful on the bridge, but there is still an important difference.

In addition, planning is a fourth function that overlaps the three functions previously described. This involves shortterm strategic planning, e.g. the next $12 \mathrm{~h}$ at a time: what do the ice and weather forecasts predict; how many vessels will need assistance and in what order; how do the priorities change if one icebreaker becomes unavailable. Those are just a few issues that need to be carefully considered. Longterm planning is also important, which is mainly done by the masters of the icebreakers, and includes e.g. arranging crew rotation schemes during the whole winter season. This is vital to ensure that competency is distributed evenly between the different crews, and a good example of how TOC can be utilized to address constraints. If lack of experience is viewed as a constraint, thoughtful planning can mitigate the negative effect of unexperienced crew members.

\subsubsection{Object-related processes and physical objects}

The four purpose-related functions can be further broken down into object-related processes, which in turn require a number of physical objects and resources. The processes were found to be ice assessment, direct icebreaking, personal interaction, communication, short-term plan and longterm plan. The resources listed at the bottom of Fig. 1 are the most important ones. It is acknowledged that these objects can be further broken down and exemplified at great detail; however, for this study that is not deemed necessary. Below is a more detailed description of the meaning of the physical objects.

- Ice data includes imagery from satellites and helicopter surveillance when necessary.

- Vessel characteristics include the technical aspects that distinguish an icebreaker from a merchant vessel, e.g. four propellers, diesel electric propulsion, good manoeuvring capability, hull shape, the vessel's deadweight and engine effect.
- Electronic navigation equipment includes GPS, AIS, ECDIS, and the capability to visually display AIS tracks on, e.g. the ECDIS.

- Communication equipment includes both short range equipment, e.g. VHF, and long-range equipment, e.g. satellite phone, e-mail, IB-net and internet connection with large bandwidth.

- IB-net and IB-plot are software used by the Finnish and Swedish icebreakers for communication and monitoring of shipping activities.

- Information from other actors can be, e.g. estimated arrivals and departures from a certain port. Even though this is not a physical object, obtaining information from other parties was stressed by the respondents as very important.

- Weather sensors, most importantly the wind direction and speed.

- Weather forecasts, which are used to anticipate ice movements.

\subsection{Situations that increase cognitive load}

Situations that increase the cognitive load for icebreaker officers can be divided into four categories: external factors such as weather, wind, ice conditions and darkness; geographical factors; technical malfunctions; and human interaction.

Severe weather and tough ice conditions naturally make icebreaking more difficult, especially rapidly changing weather. What is more, uncertainty of the weather and ice forecasts' accuracy creates a situation that is difficult to prepare for. One respondent described this challenge and possible outcome:

We have a few examples where we have seen much more wind and stuff, where the forecast has been way off, and everything gets really messy if there is lots of ice, that's the way it is. And the other way around as well, there have been storm and hurricane warnings but then it hasn't been that bad, and then you might have stopped vessels and closed ports unnecessarily, but better being safe than sorry.

Paradoxically, too little ice impacts performance negatively, at least seen over the whole winter season. A concern that the respondents expressed was that of mild winters, or more exactly short winter seasons with only light ice conditions. A short season offers little time to practice and maintain one's skills, and light ice conditions with many idle hours for the icebreaker offer another challenge. For example, when monitoring several vessels in light ice where very little action is needed from the icebreaker, it is easy to let one's guard down and suddenly find oneself in a 
situation where things rapidly progress in the wrong direction. In safety research this is known as the disaster incubation period, during which 'a chain of concealed errors and other partially understood events build up in a way that is at odds with the existing beliefs and norms about hazards' (Pidgeon 2010), resulting in a gradual drift towards failure (Dekker and Pruchnicki 2013).

Darkness as an external factor has double impact. For the vessel under assistance, daylight makes observing the icebreaker easier and its manoeuvres clearly noticeable. For the icebreaker crew, however, in darkness, a powerful search light can be used to cast shadows on the ice. These shadows outline the structure of the ice more clearly than in bright day light, revealing valuable information about the ice. As a rule of thumb, the respondents agreed that darkness affects the assisted vessel negatively, while the icebreaker operates well during all hours.

Geographical areas can pose cognitive challenges in several ways. First, different areas have diverse characteristics, e.g. strong currents or ice that accumulates in difficult locations, hence a good icebreaker officer needs to gain experience from multiple areas, preferably all. Second, during mild winters, the icebreakers spend less time in southern areas with light or no ice, and with several consecutive such winters, geographical knowledge from those areas quickly diminishes. Third, cooperation with other actors in those regions, such as pilots and ship agents, becomes less regular and can thus impede the interaction. These factors can cause problems individually, or come together in creating a complex situation. One example offered is that of South Kvarken, the narrow strait between Finnish Åland and Sweden:

Looking at South Kvarken for example, where we don't operate often, lots of currents going in and out, relatively narrow passage, lots of sliding ice which creates sharp [ice] edges, for example. That requires quite a lot of experience, to know how to tackle the ice. We don't know the vessels trafficking that area, like the ferries down there, in the same way we know the vessels up here. Further south the vessels are larger, compared to up here. /... / And not as experienced in ice.

Altogether, when several factors converge, the cognitive workload is increased.

Technical malfunctions, such as the sudden loss of power, even though they occur infrequently, increase the cognitive load. However, there need not be an actual technical incident; just knowing that the risk exists can be enough. During physical assistance, the safety margins are small, and knowing that one of the generators might fall out can induce stress:

I think along the same line, but with the engines, that the propellers fall out. You start to think about that when you really need to be able to trust the vessel, because we have all been there; suddenly, the alarm goes off and the screens turn all red, and you have to make a split-second decision where to go not to get hit by the vessel astern. So one hopes that the engines will deliver.

Unfortunately, the risk of losing power increases with the severity of the ice conditions.

Finally, human interaction is an essential part of most icebreaker purpose-related functions. When not getting through to the other party, for instance when a person fails to understand or comply with an instruction, a situation can deteriorate. Not having access to the same information makes communication complex:

In this case, we see for instance a satellite image, we see all the interrelated vessels, we have vessel schedules and a planned sequence, but the vessel we are talking to, he [the person listening] only has a voice in the receiver, more or less; to express oneself in a way so that he understands what we mean without looking at the same image; he should have the information that we deliver, and interpret it the way that we want.

Even without any extraordinary language difficulties, such as different levels of language proficiency, it can be challenging to explain a situation or task at hand to a vessel under assistance, with voice communication as the only means of transfer. Limited information of icebreaker operations or inexperience adds complexity to communication.

\section{Discussion}

Although the data presented in this study illustrates the work domain of nautical officers on board icebreakers, the icebreaker itself is only one part of the complete system needed to fulfil the domain purpose; other entities are necessary for successful icebreaking. With regard to the operation of the icebreaker, the Swedish Maritime Administration is responsible for the overall governance of the operations and long-term planning, and a management company is in charge of the day-to-day operations, by e.g. ensuring sufficient manning of the icebreakers, administrating purchase orders and ship maintenance, and keeping onboard documents up to date. Since Swedish and Finnish icebreakers cooperate closely, a similar structure can be said to exist around the Finnish icebreakers, with multiple parties involved. Hence, in relation to the domain purpose, the icebreaker does not fulfil that purpose on its own. However, the reverse reasoning is still true; the sole purpose of the icebreaker is to support seagoing transportations and ensure safe navigation. 


\subsection{Constraints}

The work domain, as depicted in the previous section, shows three values and priority measures. At times, safety and efficiency might be competing values. For example, it was agreed among the respondents that safety between vessels always is highly prioritized. However, so is also efficiency, and consequently, when in conflict there has to be a tradeoff between the two. Salmon et al. (2015) reported similarly competing functional purposes when examining railway crossings; the implementation of a specific safety barrier was unlikely in the light of a strong focus on efficiency. Regarding the safety and efficiency of icebreaker operations, safety seems to have the upper hand; if conditions are deemed too severe or uncertain, the operation stops until the conditions improve, or the situation has been investigated fully. Stopping the operation inevitably leads to a time delay and decreased efficiency, and the fact that the crew feels confident enough to stop the operation can be regarded as a display of maturity under time pressure. Belling et al. (2015) speculated that the effect of time pressure possibly varies with domain; within a domain where time often is critical, such as during icebreaker operations, negative effect is less prominent. Finally, the third value of maintaining legitimacy should not be underestimated. Icebreaker operations are by nature legitimated by severe winter seasons, and consequently, following a number of consecutive mild winters, their reputation becomes tarnished.

An unexpected finding of this study is the limited economic constraint on icebreaker operations. Previous studies within other domains often highlight the financial impact on performance or decision [see e.g. Birrell et al. (2012) and Effken et al. (2011)]. The prospect of having an increased budget is appealing; however, no matter how generous a budget is, there will be times when it is not enough. Jokingly, one respondent said that 'no matter if you have five or 20 icebreakers, when you encounter extreme conditions there will still be delays'. Even with 20 icebreakers, eventually there will be a need for a 21 st icebreaker. The belief that a winter season more severe than predicted will come with an extended budget, is likely well founded. Since the overall purpose of the icebreaker is to secure a functioning infrastructure for the production industry, an operational icebreaker service is a global concern. However, it must not be forgotten that this view represents only the respondents of this study. With an organizational or management perspective, it is possible that more pressing financial constraints would have been revealed.

By looking at the means-ends links between the purposerelated functions and object-related processes in Fig. 1, it becomes apparent that icebreaker operations are not only concerned with breaking ice, at least not in the literal sense. The object-related process of direct icebreaking is crucial, but only when physically assisting another vessel, whereas communication and personal interaction are essential ingredients in several purpose-related functions. It can be argued that communication is needed for the planning of the operation as well. However, that type of communication is mainly internal, to facilitate the exchange of ideas among the crew on board the icebreaker, and does not pose the same challenges as external communication, as the parties are familiar with each other and communicate face-to-face rather than through means of radio communication. The constraint of external communication confirms previous research by Jalonen et al. (2005), who also listed problems in radio communication as one of the major hazards to winter navigation in the Gulf of Finland. If the recipient of a message does not fully understand what is being communicated by the icebreaker, while the icebreaker officer simultaneously is occupied with directing, assisting or monitoring a vessel, it constrains the work as valuable cognitive resources have to be spent on solving miscommunication.

Personal interaction can also be a constraint during icebreaker operations, however, that is not necessarily related to lack of training, but primarily to the frequency with which the interaction occurs. Human to human interaction needs to be practiced and maintained, something that is important for both parties involved. Also, interacting competently with one actor does not necessarily mean that the interaction will work well with other actors. As a result, in areas where the icebreaker operates less frequently, e.g. only during severe winters, interaction with pilots and ship agents can be problematic. Since the severity of the winter season is unpredictable, there is no easy solution to this problem. Nonetheless, reverting to TOC by addressing this constraint, the effects can be mitigated. It is common practice for Swedish icebreakers to alternate between different areas of operation, as well as to rotate the role as acting coordinator of an area. This ensures optimal familiarity with vast geographical areas, continuous interaction with local actors, and the distribution of leadership experience among icebreaker officers, which comes with the task of coordinating several icebreakers.

Another crucial skill is the ability to interpret ice, a task that requires input from external sensors in combination with previous experience of ice and its characteristics. This is a skill that guides icebreaker officers when deciding the most appropriate action in response to the present ice and weather condition, in any given situation. Consequently, this ability is of great importance as it directly influences the effectiveness and safety of icebreaker operations. The necessity of interpreting ice extends to merchant vessels as well, and an inability to do so constraints their independent navigation through ice. Previous research recommends better use of electronic navigational equipment (Valdez Banda et al. 2016), e.g. by displaying past track of other vessels (Boström 
and Österman 2017). This would assist inexperienced crews and mitigate the constraint of ice assessment. Furthermore, based on accident statistics and expert judgments, Valdez Banda et al. (2015) state convoy operation to be the most complex and accident-prone operation performed by icebreakers. With three object-related processes identified as ice assessment, personal interaction and communication, it can be argued that this study supports the previous claim by Valdez Banda et al. (2015); lacking these three abilities would make convoy operations a difficult and even more hazardous task.

The cognitive constraints that have been discussed above involve some of the elements that Vicente (1999) uses to characterize a complex socio-technical system. The constraints from communication and interaction pose a challenge to the actor because it requires social interaction between numerous individuals with heterogeneous perspectives, and the interpretation of ice is difficult due to its high degree of uncertainty. Reverting to TOC, attention should be paid to these constraints to investigate how they can be utilized to their advantage (Rahman 1998), thus increasing the efficiency and operational safety of icebreaker operations.

\subsection{Situations that increase cognitive load}

A common denominator for the situations identified as increasing cognitive workload is that they add elements of uncertainty, e.g. not knowing the manoeuvrability of the icebreaker under severe weather conditions, not recognising local geographical phenomena such as currents, not knowing whether one can rely on the vessel's technical capability, or not knowing the level of experience of the crew receiving assistance. Lipshitz and Strauss (1997) propose that 'uncertainty in the context of action is a sense of doubt that blocks or delays actions'. The elements of uncertainty listed above illustrate a dynamic environment, which requires icebreaker officers to have a mental contingency plan in place, with several options depending on how the situation develops. Consequently, preparing for the unknown increases the cognitive demand on the actor.

The disagreement concerning what constitutes a good winter season, with opposing views represented on one side by the interviewed respondents of the icebreakers, and on the other by merchant vessels, is a topic that deserves to be highlighted. For merchant vessels, it is likely that a short winter season with only light to moderate ice conditions is preferred. This is derived from the argument that ice only has negative implications for a merchant vessel; ice reduces the average speed of the vessel and increases fuel consumption, it increases the wear and tear of the vessel with higher maintenance costs as a result, and adds cognitive, as well as physical constraints on crewmembers unfamiliar with cold and ice. In contrast, the results clearly show that the opposite is desirable for the icebreakers. The icebreakers favour tough ice conditions as such ice has less tendency to shift, thus reducing one uncertainty from the cognitive workload. Furthermore, long winter seasons offer great possibilities to practice and maintain necessary icebreaker skills, both practical hands-on skills such as manoeuvring as well as cognitive skills. This is, therefore, a prerequisite for maintaining icebreaker competence on an individual level, as well as ensuring a supply of newly qualified icebreaker officers. A long ice season is likely to provide a new icebreaker candidate with sufficient training to receive the ice endorsement required for qualification as icebreaker officer. With shortage of ice and insufficient training, a candidate might be required to spend another winter season on board before qualifying, which acts as a deterrent for his or her future engagement. The situation is further complicated by the fact that icebreakers partly rely on seasonally employed personnel during the winter and with a shorter season, the workforce needed will likely be smaller. Uncertainty about the availability of work makes seasonal employment less attractive; hence, the unpredictability of the winter season is a potential constraint for the retention of skilled icebreaker officers. However, if a seasonal employment on board an icebreaker could be combined with another employment, the seasonal variation of winters would be less acute. A possible collaborator could be a shipping company operating passenger ferries with seasonal summer peaks. With relative small means, such a collaboration would have potential to retain experienced personnel within two organizations, and hopefully offer an improved employment stability for the individual. If that were possible, the effect of the constraint posed by unpredictable winters would be reduced, and the overall performance of the icebreaker improved. In accordance with the main philosophy of TOC, the subsequent step would then be to re-examine the system to identify new constraints and look for further ways towards improvements.

\subsection{Limitations}

Since respondents and the subject matter expert were recruited from Swedish icebreakers, this study consequently only depicts the constraints on Swedish icebreakers in Baltic Sea operations. Moreover, since a WDA is a description of the constraints or conditions under which a task is carried out, these constraints may very well vary between different geographical, cultural or political arenas. Furthermore, the study is exploratory in its nature and should be viewed as a first step towards determining the direction of future research within the area of icebreaker operations, rather than offering a detailed account. The study is also limited to the nautical department of an icebreaker. There are likely to be constraints caused by interdepartmental interactions, such as conflicting interests regarding optimal engine power 
output. However, these are not taken into consideration by this study.

\section{Conclusions}

This study, as it was designed, shows the work domain analysis to be an efficient means to depict the constraints outlining the operation of an icebreaker. Icebreaker operations are complex and involve elements of risk. The holistic approach of the WDA offers a multifaceted view of the system and its constraints, with focus on both humans, technology and environment. The work of an icebreaker can roughly be divided into two sets of activities: activities that are traditionally associated with actual ice operations, such as ice assessment and direct icebreaking, and activities that are vital but less explicit, such as personal interaction and communication. The first set is strongly dependent on, and therefore, also constrained by, technical attributes such as the availability and accuracy of ice data, weather forecasts and the icebreaker itself. This is the area of ice navigation that has been most researched in the past. The second set, however, is constrained by personal abilities such as language and social abilities. Miscommunication, for example, has the potential to increase the officer's stress level. The problem is not primarily the lack of technical means to communicate, but more related to getting the meaning across. One value that does not fit any of the two categories is that of gaining and maintaining legitimacy. Even though this only has limited bearing on the everyday operation of icebreakers, the public opinion is important for long-term legitimacy and the justification of the way icebreakers operate.

A number of conflicting constraints have been identified. First, the variation of the severity of the winter seasons is problematic to icebreakers, both at individual and organisational level. At individual level, a short winter season makes it harder to maintain one's icebreaker skills. At organisational level, this makes it more difficult to motivate and retain seasonally employed personnel. However, in contrast, ice generally makes seagoing transportations in the Baltic Sea more difficult and costly for shipping in general. Second, operations during night-time present a similar case. Darkness is deemed a constraint for the assisted vessel, yet a possible advantage for the icebreaker officers as a strong search light provides a detailed picture of the ice. Consequently, something that is a constraint for one party can be of value for another. Third, from the icebreaker perspective, there exists a conflict between the values of safety and efficiency; during tough situations, safety sometimes comes at the expense of efficiency. While this might not come as a surprise, it does once again illustrate the complexity of the operation.
The situations that increase cognitive workload can be linked to elements of uncertainty; the cognitive load increases with the number of uncertain elements. This is a special concern in situations including, e.g. severe weather and ice conditions, technical malfunctions and human interaction. Unfortunately, the occurrence of several uncertainties at once is not uncommon, e.g. severe weather and ice conditions make ice assessment difficult (uncertainty about ice), requiring a high engine effect (uncertainty about technical capability).

Finally, a WDA focuses on the constraints that restrict the work of the operator, rather than describe or prescribe a standard operating procedure. A continuous focus on the constraints, and an ambition to use them to one's advantage, are cornerstones of TOC. This study has identified a number of instances where constraints already have been addressed by icebreaker officers. The most prominent such constraint is the unpredictability of winter seasons, where the negative effect is mitigated by a deliberate rotation of responsibilities and areas of operation. However, the description of icebreaker operations and its constraints presented in this study is a suitable way to identify further research needs, leading to a systematic increase of knowledge within the area of ice navigation and icebreaker operations. Future research within this area could include performing a complete CWA with all five phases, to get a more thorough understanding of how the identified constraints are addressed on board. Another step would be to investigate how meaning is transferred successfully between vessels, how cultural aspects can be manifested, e.g. as misunderstandings, and how those effects can be mitigated in critical situations.

Open Access This article is distributed under the terms of the Creative Commons Attribution 4.0 International License (http://creativeco mmons.org/licenses/by/4.0/), which permits unrestricted use, distribution, and reproduction in any medium, provided you give appropriate credit to the original author(s) and the source, provide a link to the Creative Commons license, and indicate if changes were made.

\section{References}

Akhtar MJ, Utne IB (2014) Common patterns in aggregated accident analysis charts from human fatigue-related groundings and collisions at sea. Marit Pol Manag 42:1-21. https://doi. org/10.1080/03088839.2014.926032

Belling P, Suss J, Ward P (2015) The effect of time constraint on anticipation, decision making, and option generation in complex and dynamic environments. Cogn Technol Work 17:355-366. https:// doi.org/10.1007/s10111-015-0334-2

Birrell SA, Young MS, Jenkins DP, Stanton NA (2012) Cognitive Work Analysis for safe and efficient driving. Theor Issues Ergon Sci 13:430-449. https://doi.org/10.1080/1463922X.2010.539285

Boström M, Österman C (2017) Improving operational safety during icebreaker operations. WMU J Marit Aff 16:73-88. https://doi. org/10.1007/s13437-016-0105-9 
Bourne LE, Yaroush RA (2003) Stress and cognition: a cognitive psychological perspective. University of Colorado, USA

Braun V, Clarke V (2006) Using thematic analysis in psychology. Qual Res Psychol 3:77-101. https://doi.org/10.1191/1478088706qp063 oa

Buysse J (2007) Handling ships in ice: a practical guide to handling class $1 \mathrm{~A}$ and $1 \mathrm{AS}$ ships. The Nautical Institute, London

Chai T, Weng J, De-qi X (2017) Development of a quantitative risk assessment model for ship collisions in fairways. Saf Sci 91:7183. https://doi.org/10.1016/j.ssci.2016.07.018

Chambers TP, Main LC (2015) Symptoms of fatigue and coping strategies in maritime pilotage. Int Mari Health 66:43. https://doi. org/10.5603/IMH.2015.0011

Dekker S, Pruchnicki S (2013) Drifting into failure: theorising the dynamics of disaster incubation. Theor Issues Ergon Sci. https:// doi.org/10.1080/1463922X.2013.856495

Denzin NK, Lincoln YS (2011) The Sage handbook of qualitative research. Sage, Thousand Oaks

Dhukaram AV, Baber C (2015) Modelling elderly cardiac patients decision making using Cognitive Work Analysis: identifying requirements for patient decision aids. Int J Med Inform 84:430-443. https://doi.org/10.1016/j.ijmedinf.2015.01.001

Effken JA, Brewer BB, Logue MD, Gephart SM, Verran JA (2011) Using Cognitive Work Analysis to fit decision support tools to nurse managers' work flow. Int J Med Inform 80:698-707. https ://doi.org/10.1016/j.ijmedinf.2011.07.003

Elfering A, Grebner S, Leitner M, Hirschmüller A, Kubosch EJ, Baur H (2017) Quantitative work demands, emotional demands, and cognitive stress symptoms in surgery nurses. Psychol Health Med 22:604-610. https://doi.org/10.1080/13548506.2016.1200731

Etikan. I, Musa. SA, Alkassim. RS (2016) Comparison of Convenience Sampling and Purposive Sampling. Am J Theor Appl Stat. https ://doi.org/10.11648/j.ajtas.20160501.11

Gillham B (2005) Research interviewing: the range of techniques. Open University Press, Maidenhead

Goerlandt F, Montewka J, Zhang W, Kujala P (2017) An analysis of ship escort and convoy operations in ice conditions. Saf Sci 95:198-209. https://doi.org/10.1016/j.ssci.2016.01.004

Goldratt EM (1988) Computerized shop floor scheduling. Int J Prod Res 26:443-455. https://doi.org/10.1080/00207548808947875

Hetherington C, Flin R, Mearns K (2006) Safety in shipping: the human element. J Safety Res 37:401-411. https://doi.org/10.1016/j. jsr.2006.04.007

Hockey RJ (1997) Compensatory control in the regulation of human performance under stress and high workload: a cognitive-energetical framework. Biol Psychol 45:73-93. https://doi.org/10.1016/ S0301-0511(96)05223-4

House D, Toomey P, Lloyd M, Dickins D (2010) The ice navigation manual. Witherby Seamanship International Ltd., Edinburgh

Jalonen R, Riska K, Hänninen S (2005) A preliminary risk analysis of winter navigation in the Baltic Sea. Winter Navigation Research Board, Research Report No 57

Karahalios H (2014) The contribution of risk management in ship management: the case of ship collision. Saf Sci 63:104-114. https:// doi.org/10.1016/j.ssci.2013.11.004

Kitzinger J (1994) The methodology of focus groups: the importance of interaction between research participants. Soc Health Illn 16:103121. https://doi.org/10.1111/1467-9566.ep11347023

Kujala P, Arughadhoss S (2012) Statistical analysis of ice crushing pressures on a ship's hull during hull-ice interaction. Cold Reg Sci Technol 70:1-11. https://doi.org/10.1016/j.coldregion s.2011.09.009

Lind M (2003) Making sense of the abstraction hierarchy in the power plant domain. Cogn Technol Work 5:67-81. https://doi. org/10.1007/s10111-002-0109-4
Lipshitz R, Strauss O (1997) Coping with uncertainty: a naturalistic decision-making analysis. Organ Behav Hum Decis Process 69:149-163. https://doi.org/10.1006/obhd.1997.2679

Naikar N (2005a) A methodology for work domain analysis, the first phase of cognitive work analysis. Proc Hum Factors Ergon Soc Annu Meet 49:312-316. https://doi.org/10.1177/1541931205 04900321

Naikar N (2005b) Theoretical concepts for work domain analysis, the first phase of cognitive work analysis. Proc Hum Factors Ergon Soc Annu Meet 49:249-253. https://doi.org/10.1177/1541931205 04900308

Naikar N, Sanderson PM (1999) Work domain analysis for trainingsystem definition and acquisition. Int J Aviat Psychol 9:271-290

Naikar N, Treadwell A, Brady A (2014) Cognitive work analysis beyond human factors and engineering: application to military doctrine and strategy development. Proc Hum Factors Ergon Soc Annu Meet 58:330-334. https://doi.org/10.1177/1541931214 581068

Pidgeon N (2010) Systems thinking, culture of reliability and safety. Civ Eng Environ Syst 27:211-217. https://doi.org/10.1080/10286 608.2010.482660

Rahman S-u (1998) Theory of constraints: a review of the philosophy and its applications. Int J Oper Prod Manag 18:336-355. https:// doi.org/10.1108/01443579810199720

Rasmussen J (1985) The role of hierarchical knowledge representation in decisionmaking and system management. IEEE Trans Syst, Man Cybern SMC 15:234

Regan MA, Lintern G, Hutchinson R, Turetschek C (2015) Use of cognitive work analysis for exploration of safety management in the operation of motorcycles and scooters. Accid Anal Prev 74:279-289. https://doi.org/10.1016/j.aap.2014.07.009

Ronen B, Spector Y (1992) Managing system constraints: a cost/ utilization approach. Int J Prod Res 30:2045-2061. https://doi. org/10.1080/00207549208948137

Salmon PM et al (2015) More than meets the eye: using cognitive work analysis to identify design requirements for future rail level crossing systems. Appl Ergon. https://doi.org/10.1016/j.aperg o.2015.06.021

Simon HA (1996) The sciences of the artificial, 3 edn. MIT Press, Cambridge

Şimşit ZT, Günay NS, Vayvay Ö (2014) Theory of constraints: a literature review. Procedia Soc Behav Sci 150:930-936. https://doi. org/10.1016/j.sbspro.2014.09.104

Snider D (2012) Polar ship operations—a practical guide. The Nautical Institute, London

Stanton NA, Bessell K (2014) How a submarine returns to periscope depth: analysing complex socio-technical systems using Cognitive Work Analysis. Appl Ergon 45:110-125. https://doi.org/10.1016/j. apergo.2013.04.022

Stanton N, Salmon P, Rafferty L, Walker G, Baber C, Jenkins D (2013) Human factors methods: a practical guide for engineering and design. Ashgate Publishing Company, Burlington

Stewart DW, Shadmasani PN, Rook DW (2007) Focus groups: theory and practice, 2nd edn. SAGE, Thousand Oaks

Strauch B (2015) Investigating fatigue in marine accident Investigations. Procedia Manufac 3:3115-3122. https://doi.org/10.1016/j. promfg.2015.07.859

Valdez Banda OA, Goerlandt F, Montewka J, Kujala P (2015) A risk analysis of winter navigation in Finnish sea areas. Accid Anal Prev 79:100-116. https://doi.org/10.1016/j.aap.2015.03.024

Valdez Banda OA, Goerlandt F, Kuzmin V, Kujala P, Montewka J (2016) Risk management model of winter navigation operations. Mar Pollut Bull 108:242-262. https://doi.org/10.1016/j.marpo lbul.2016.03.071 
Vicente KJ (1999) Cognitive work analysis: toward safe, productive, and healthy computer-based work. Lawrence Erlbaum Associates, Inc., Mahwah

Waller MJ, Gupta N, Giambatista RC (2004) Effects of adaptive behaviors and shared mental models on control crew performance. Manage Sci 50:1534-1544. https://doi.org/10.1287/mnsc.1040.0210
Xiao T, Sanderson P (2014) Evaluating the generalizability of the Organizational Constraints Analysis framework: a hospital bed management case study. Cogn Technol Work 16:229-246. https ://doi.org/10.1007/s10111-013-0260-0 